\title{
Analysis of chemical polymerization between functionalized MWCNT and poly(furfuryl alcohol) composite
}

\author{
Elilton Rodrigues Edwards ${ }^{1 *}$, Silvia Sizuka Oishi² and Edson Cocchieri Botelho ${ }^{3}$ \\ ${ }^{1}$ Department of Exact Sciences and Technology, Universidade Estadual de Santa Cruz - UESC, \\ Ilhéus, BA, Brazil \\ ${ }^{2}$ LAS, Instituto Nacional de Pesquisas Espaciais - INPE, São José dos Campos, SP, Brazil \\ ${ }^{3}$ Department of Materials and Technology, Universidade Estadual Paulista - UNESP, \\ Guaratinguetá, SP, Brazil \\ *eredwards@uesc.br
}

\begin{abstract}
In this study, the chemical interaction between functionalized carbon nanotuboes with carboxyl groups (CNT-f) and the subsequent addition of furfuryl alcohol (FA) and mixture with poly(furfuryl alcohol) (PFA) resin was evaluated. The FA with CNT-f was mixed in PFA resin to facilitate the chemical interaction of CNTs. The morphological and chemical interaction were studied by Transmission Electron Microcopies (MET), FTIR analyses, Raman Spectroscopy, viscosimetry and X-ray photoelectron spectroscopy (XPS). It was observed that a chemical interaction occurs through the opening of the hydroxyl polymer chain with a subsequent output of one water molecule. This interaction was evident from the FTIR and XPS data of the PFA composites. In this way, the mixture of functionalized carbon nanotubes with carboxyl groups in the FA, before adding this reinforcement into the PFA resin, can be considered a good procedure in order to obtain an appropriate chemical interaction between the CNT and PFA resin.
\end{abstract}

Keywords: nanostructured composite, chemical properties, surface analysis, cure reaction.

\section{Introduction}

Poly(furfuryl alcohol) (PFA) is a thermosetting resin of furan class which has gained great importance mainly due to it being obtained from renewable resources ${ }^{[1,2]}$. Nowadays, this resin has a wide range of applications such as adhesives, glassy carbon nanoporous, polymer nanocomposites, etc ${ }^{[3,4]}$. Many studies have been undertaken to develop thermoplastic and thermosetting polymer composites with multiwall carbon nanotubes (MWCNT) as the reinforcing element ${ }^{[5,6]}$.

According to the literature ${ }^{[7-10]}$, by introducing small amounts of carbon nanotubes (CNTs), the mechanical, electrical and thermal properties of composite materials can be improved. However, it is generally known that CNTs are not compatible with most solvents available on the market because of the chemical inertness. In addition, it is difficult to obtain a homogeneous solution, resulting in poor dispersion capability of CNT into polymeric resins and weak interfacial interactions inside composite materials.

The mechanical and electrical properties of a polymer composite with CNT reinforcement depends on the dispersion and good chemical interaction between CNT and polymer matrix ${ }^{[7,8]}$. The literature ${ }^{[7-10]}$ includes several possible mechanisms of polymerization of furfuryl alcohol with different types of catalysts, but until now there is no understanding about the chemical interaction between carbon nanotubes and PFA.

In this study, the evaluation of the chemical interaction between functionalized CNT and PFA resin cured with p-toluene sufonic acid (PTSA) is presented. PFA composites were manufactured with 0 and $0.5,1.0$ and $2.0 \mathrm{wt} \%$ of functionalized CNT. The CNTs and composites of PFA/functionalized CNT were characterized using XPS, transmission electron microscopy (TEM), viscosimetry, Raman and FTIR spectroscopies. From these results, a mechanism of chemical interaction between CNT and PFA was proposed.

\section{Materials and Methods}

\subsection{Materials}

Multiwalled carbon nanotubes (MWCNT) were obtained from the pyrolysis of a mixture of camphor and ferrocene into a quartz tube at $850^{\circ} \mathrm{C}^{[11]}$. This mixture was evaporated at $200^{\circ} \mathrm{C}$ into a quartz tube in a tube furnace with a $200 \mathrm{sccm}$ flow of inert gas $\left(\mathrm{N}_{2}\right)$. By using this process, the growth rate of CNT was $15 \mu \mathrm{m} / \mathrm{min}$. The CNT were produced with an outside diameter ranging from 50-100 nm and a length of $\sim 100 \mu \mathrm{m}$. Poly(furfuryl alcohol) (PFA) resin was obtained from the polymerization of furfuryl alcohol (FA) using a diluted solution of sulfuric acid as a catalyst in the following proportion [furfuryl alcohol]/[acid solution] $=140$. The reaction occurred over one hour and was performed at an initial temperature of $32{ }^{\circ} \mathrm{C}$. The final viscosity of the resin was about $265 \mathrm{mPa}$.s and the moisture was less than $1.0 \mathrm{wt} \%$.

\subsection{Purification and functionalization processes}

Purification of the MWCNT was performed using conventional acid treatments with a non-oxidative process using concentrated $\mathrm{HCl}(36 \mathrm{wt} \%)$ that was sonicated in an 
ultrasound bath for $5 \mathrm{~h}$. The MWCNT were washed and filtered with a Millipore membrane $(0.45 \mu \mathrm{m}$ pore size $)$ and dried in a vacuum oven at $100{ }^{\circ} \mathrm{C}$ for $12 \mathrm{~h}$. The functionalization process was performed using oxidative treatment with a mixture of $\mathrm{H}_{2} \mathrm{SO}_{4}: \mathrm{HNO}_{3}(3: 1)$ under reflux at a temperature of between $45^{\circ} \mathrm{C}$ and $50^{\circ} \mathrm{C}$ for $5 \mathrm{~h}$ in order to add carboxylic group over the CNT walls. This material was washed until it had a neutral $\mathrm{pH}$, filtered and dried in a vacuum oven at $100{ }^{\circ} \mathrm{C}$ for $12 \mathrm{~h}$.

\subsection{Nanostructured composite manufacturing}

The nanostructured composite was processed with $0.5,1.0$ and $2.0 \mathrm{wt} \%$ of functionalized CNT into $5 \mathrm{~mL}$ of FA and sonicated for 4 mins in an ultrasonic probe. The wt $\%$ of CNT was determined from the composite mass without CNT [(FA alcohol $)+($ PFA resin $)$ cured with PTSA].
The mixture (FA+CNT-f) was mixed with $10 \mathrm{~g}$ of PFA resin and sonicated again with an ultrasonic probe for 4 mins. In both situations the temperature was controlled with an ice bath (see Figure 1). PTSA was used as a catalyst for the PFA cure at a proportion of $5.0 \mathrm{wt} \%$. The composite was cured in a mold of silicon at $50^{\circ} \mathrm{C}, 70^{\circ} \mathrm{C}, 90^{\circ} \mathrm{C}, 110^{\circ} \mathrm{C}, 130^{\circ} \mathrm{C}$ for $2 \mathrm{~h}$ in each temperature in an oven, model VUK/UV 55. Cured PFA without CNT was also obtained for comparison.

\subsection{Characterization}

Multiwall carbon nanotubes were characterized by transmission electron microscopy (TEM) using a Philips CM 120 microscope in order to evaluate the surface integrity after the oxidative functionalization process used in this study. These analyses were compared with the TEM results obtained for the purified material with $\mathrm{HCl}$. Analysis

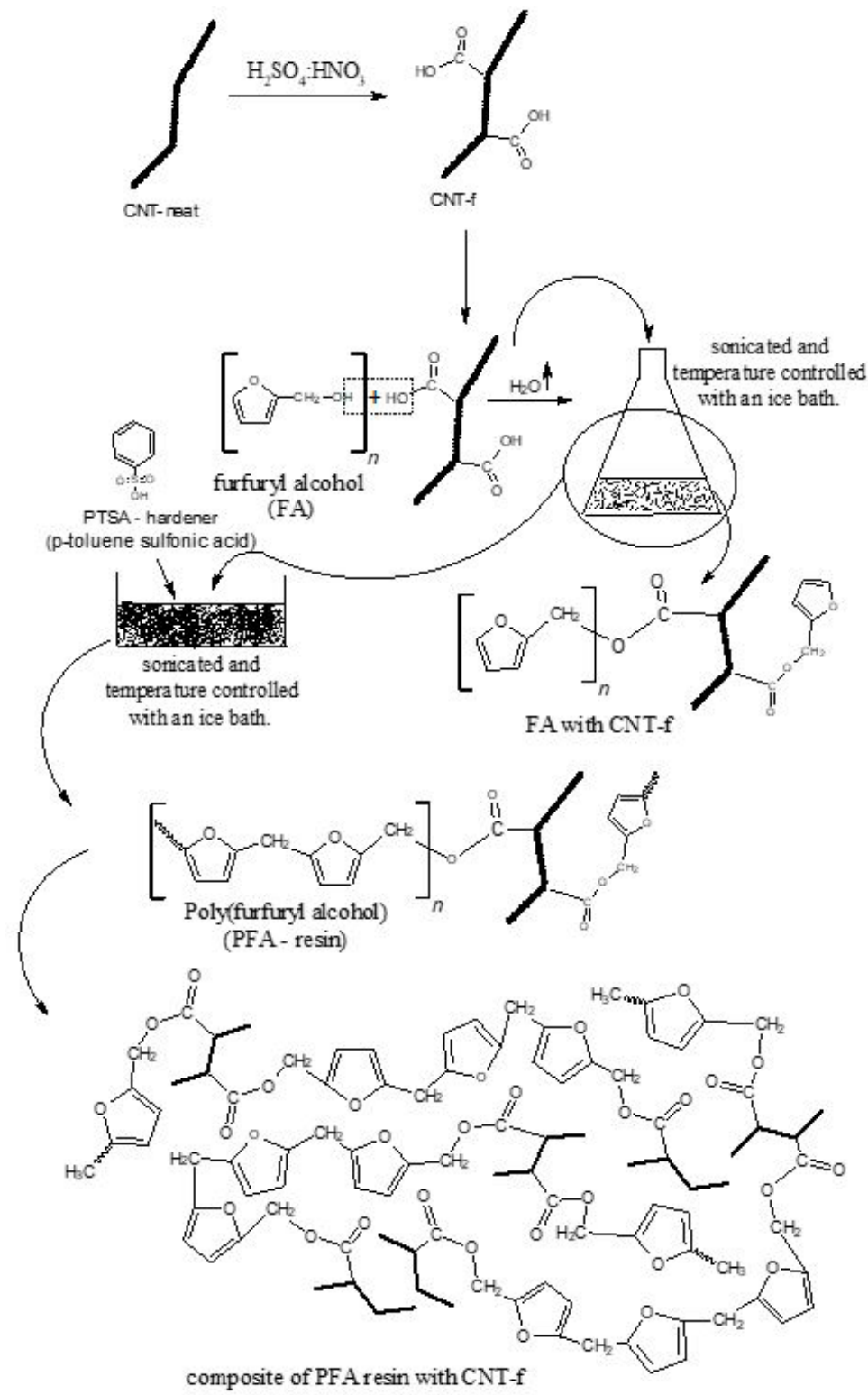

Figure 1. Synthesis rote for fabrication of composite of FPA resin with carbon nanotube functionalized. 
of the high resolution scanning electron microscopy SEM (Mod. JEOL 7500) was also performed on a cross section of the fractured composite specimen reinforced with functionalized CNT. Raman spectroscopy was performed using a Renishaw 2000 system equipped with an Ar laser (514.5 nm), ranging from 1000 to $3500 \mathrm{~cm}^{-1}$, in order to verify the integrity of the CNT powder after each treatment, based on the relative intensity of the $\mathrm{D}$ and $\mathrm{G}$ band, $\left(\mathrm{I}_{\mathrm{D}} / \mathrm{I}_{\mathrm{G}}{ }^{[12]}\right.$. A study based on $\mathrm{X}$-ray photoelectron spectroscopy (XPS) was performed to evaluate the insertion of carboxylic group onto the CNT walls. Additionally, XPS analyses were conducted using a commercial spectrometer (Model UNI-SPECS UHV). The $\mathrm{MgK} \alpha$ line used was $\mathrm{h} v=1253.6 \mathrm{eV}$ and the analyzer pass energy was set up to $10 \mathrm{eV}$. The inelastic background of the $\mathrm{C}_{1 \mathrm{~s}}, \mathrm{O}_{1 \mathrm{~s}}$ and electron core-level spectra was removed using Shirley's method. FTIR analyses were performed in a spectrometer from PerkinElmer Instruments, Spectrum 100 model, using the universal attenuated total reflectance (UATR) technique.

\section{Results and Discussions}

Figure 1 shows a schematic figure of the polymerization analysis between the functionalized MWCNT and poly(furfuryl alcohol). A chemical analysis the polymerization between the furfuryl resin polymer and functionalized MWCNT was performed.

Figure 2a shows a TEM image of the as-obtained CNTs. In this figure, the presence of iron particles into the tube in the form of small spheres can be observed. The particles of iron are derived from the ferrocene precursor used in the manufacturing process of carbon nanotubes. Figure $2 b$ shows an image of purified $\mathrm{CNT}$ with concentrated $\mathrm{HCl}$ stored for $5 \mathrm{~h}$ in an ultrasonic bath. The use of concentrated $\mathrm{HCl}$ shows that CNT both internal and external impurities, such as iron particles, are removed. A complete study in this regard was published in the references ${ }^{[13]}$. Figure $2 \mathrm{c}$ shows an image of CNT functionalized with $\mathrm{H}_{2} \mathrm{SO}_{4}: \mathrm{HNO}_{3}(3: 1)$, which is a strong oxidative acid. This acid can insert a great amount of carboxylic groups onto CNT walls, however prolonged use can destroy their walls ${ }^{[13]}$. Some authors have also reported a process of exfoliation on the CNT walls and consequent reduction in wall thickness when using oxidative acids ${ }^{[12,14]}$.

Figure 3a shows an image of the PFA composite with $2 \mathrm{wt} \%$ of CNT-f. This specimen was fractured to expose the CNTs in the material. The captured image shows the cross section of the fractured region in the composite. It is very difficult to expose the CNTs in this material because its morphology contains regions with overlapped layers in which the CNTs are wrapped, consequently only a few CNTs are exposed after fracturing. Figure $3 \mathrm{~b}$ shows the surface with higher magnification containing carbon nanotubes (with an arrow).

Figure 4 shows the Raman spectra results from the neat (a), purified (b) and functionalized (c) carbon nanotubes. The band at $1352 \mathrm{~cm}^{-1}$ ( $\mathrm{D}$ band) represents the disordered structure of carbon while $\mathrm{G}$ band at $1584 \mathrm{~cm}^{-1}$ corresponds to graphite in-plane vibrations with $\mathrm{E}_{2 \mathrm{~g}}$ symmetry. $\mathrm{I}_{\mathrm{D}} / \mathrm{I}_{\mathrm{G}}$ intensity ratio is useful to estimate the degree of organization in graphitic materials. A higher $\mathrm{I}_{\mathrm{D}} / \mathrm{I}_{\mathrm{G}}$ intensity ratio for neat CNT reveals
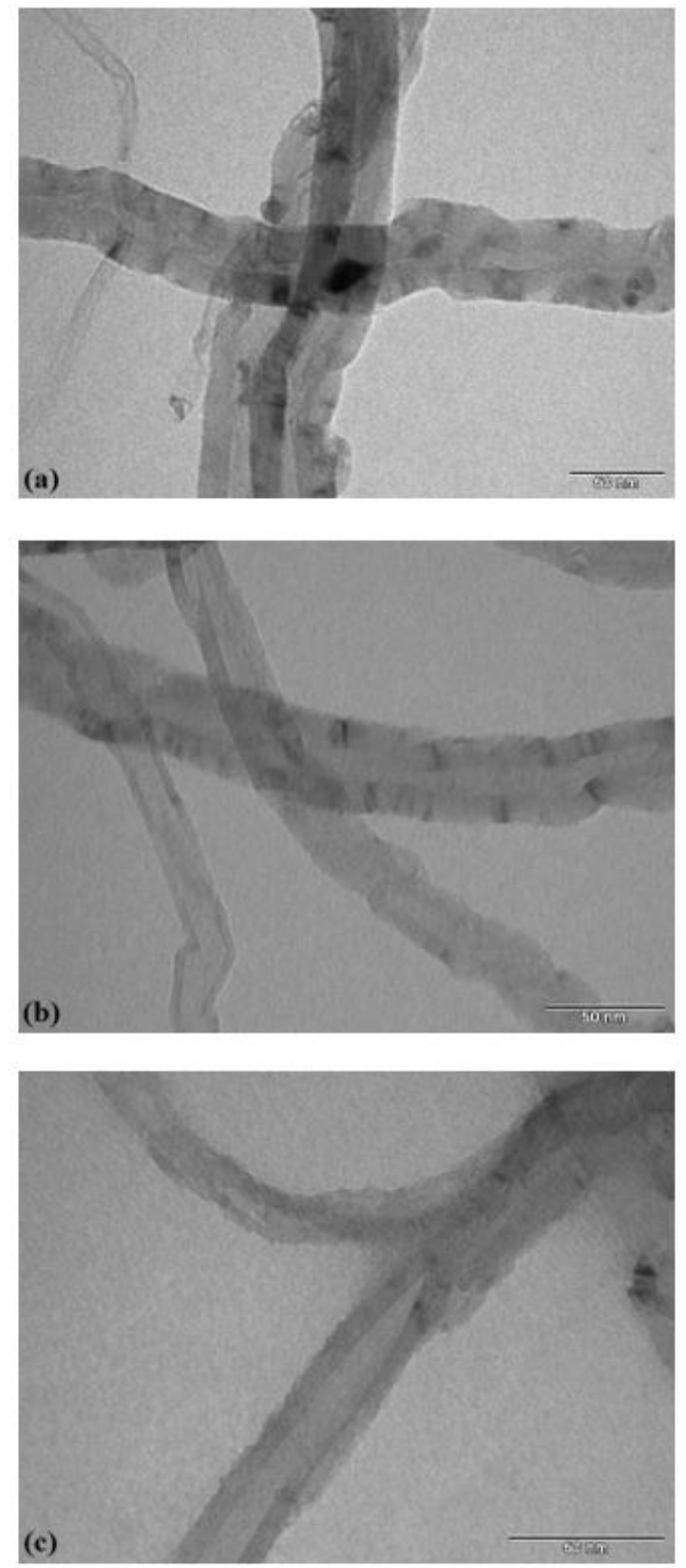

Figure 2. TEM images of: (a) CNT-as-obtained; (b) purified with $\mathrm{HCl}$-concentrated and (c) functionalized with oxidative acid $\mathrm{H}_{2} \mathrm{SO}_{4}-\mathrm{HNO}_{3}$.

a high degree of structural disorder (amorphous carbon). For purified CNT and CNT-f, a decrease in the D band and an increase in the $\mathrm{G}$ band is observed with a higher graphitic ordering after the functionalization. The higher intensity of the $\mathrm{G}^{\prime}$ band at $2706 \mathrm{~cm}^{-1}$ for CNT- $\mathrm{f}$ is indicative of a more ordered structure, which indicates that amorphous carbon was eliminated and the integrity of the CNT was maintained after functionalization.

Figure 5 shows the FTIR analysis in PFA resin synthesized in our laboratory. The bands at 732, 1150 and $1505 \mathrm{~cm}^{-1}$ correspond to furan ring. The band at $1010 \mathrm{~cm}^{-1}$ 

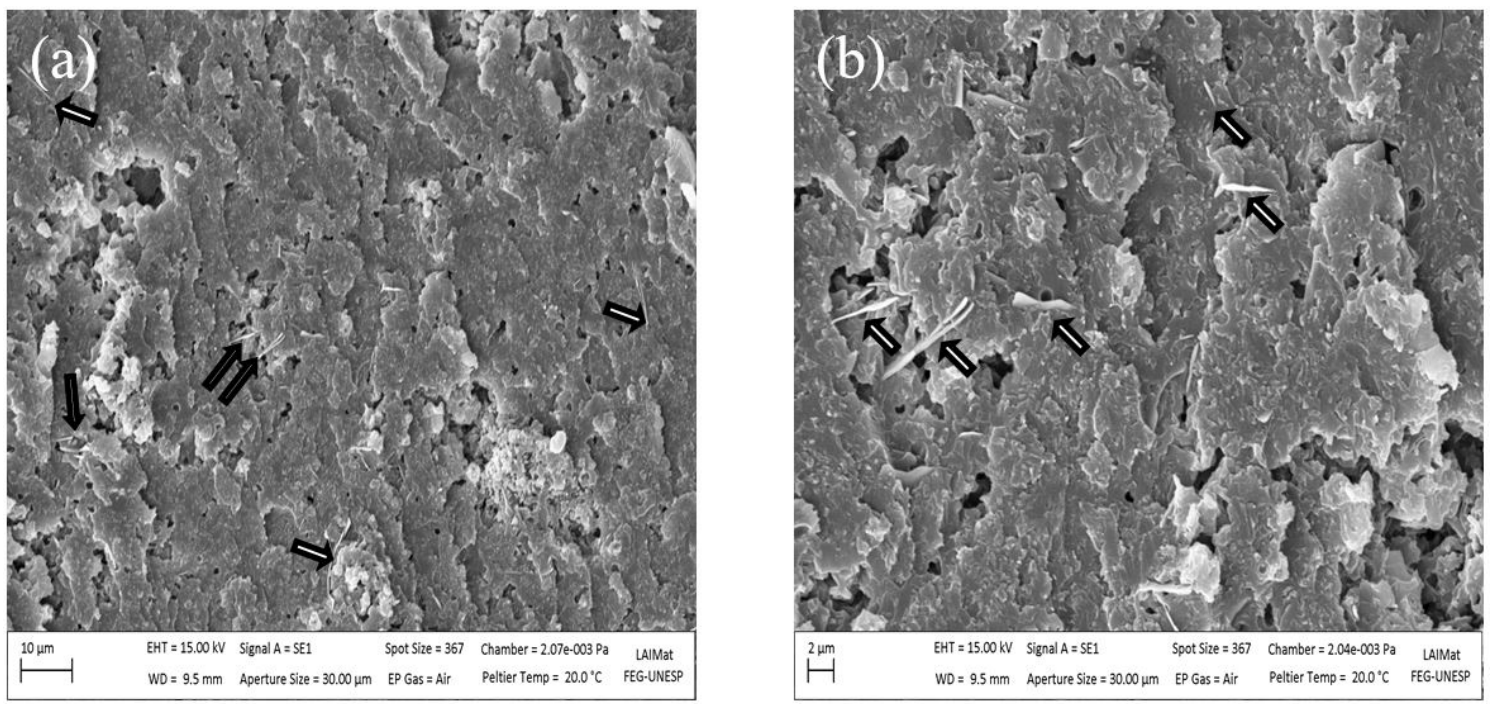

Figure 3. (a) SEM composite of PFA resin cured with CNTs functionalized (arrows pointed to the CNTs) and (b) shows the surface with higher magnification.

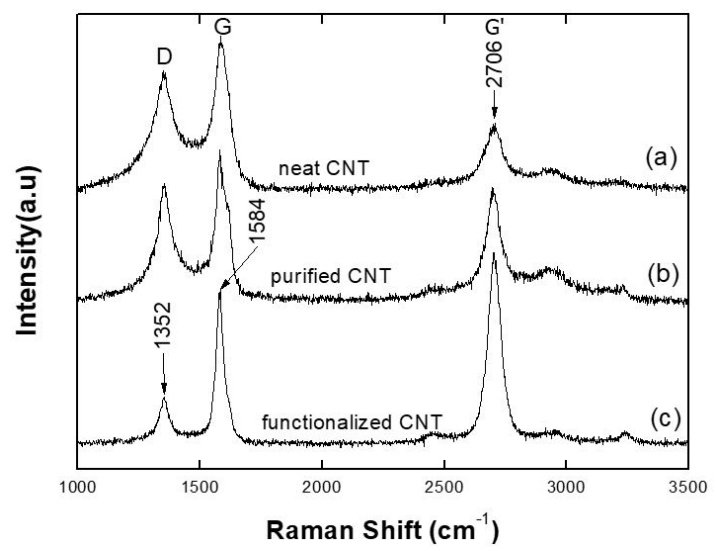

Figure 4. Raman spectra results: (a) neat CNT; (b) purified CNTs and (c) functionalized CNTs with $\mathrm{H}_{2} \mathrm{SO}_{4}: \mathrm{HNO}_{3}$.

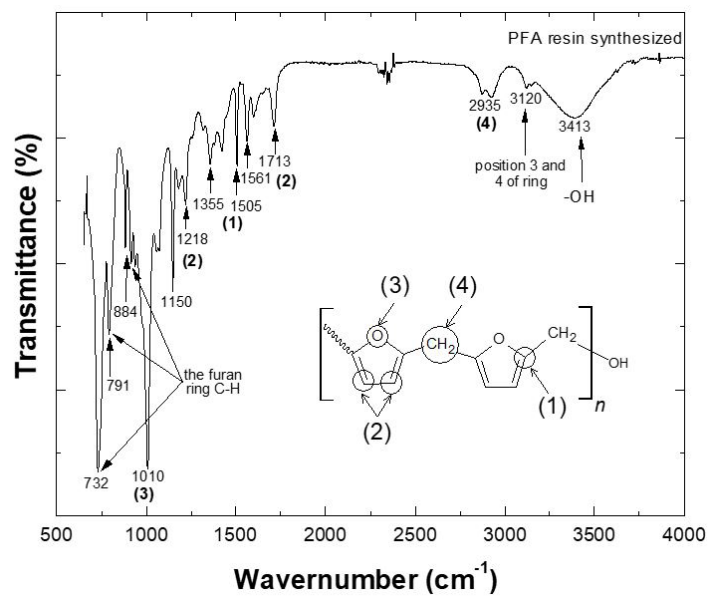

Figure 5. FTIR analysis on PFA resins synthesized in the laboratory. corresponds to the $\mathrm{vC}-\mathrm{O}$ of furan ring. The band at $1218 \mathrm{~cm}^{-1}$ is attributed to $\mathrm{C}-\mathrm{O}$ bonds from the alcohol or $\mathrm{C}-\mathrm{O}-\mathrm{C}$ of furan ring ( $v \mathrm{C}-\mathrm{OH}, v \mathrm{C}-\mathrm{O}-\mathrm{C})$. The bands of the conjugated $\mathrm{C}=\mathrm{C}$ species arise in $1355 \mathrm{~cm}^{-1}$ and $1561 \mathrm{~cm}^{-1}$. The stretching of the link $-\mathrm{CH}_{2}-\mathrm{CO}$ - emerges at $1420 \mathrm{~cm}^{-1}$. The stretching at $1713 \mathrm{~cm}^{-1}$ is related to acetone or aliphatic diketone $(v \mathrm{C}=\mathrm{O})$. The band at $2935 \mathrm{~cm}^{-1}$ suggests the presence of methyl groups and the band at $3120 \mathrm{~cm}^{-1}$ corresponds to $\mathrm{C}_{3}$ and $\mathrm{C}_{4}$ carbon. The position at $3413 \mathrm{~cm}^{-1}$ corresponds to $\mathrm{OH}$ stretch $(\mathrm{vO}-\mathrm{H})^{[15-19]}$

Figure 6a shows the FTIR spectra of cured PFA and PFA composites with $0.5,1.0$ and $2.0 \mathrm{wt} \%$ of functionalized CNTs. Comparing neat composite with the composites containing different percentages of CNT-f, the band at $730 \mathrm{~cm}^{-1}$ changes to a dominance of $792 \mathrm{~cm}^{-1}$, which is related to the reaction progress. Thus, the presence of CNT-f increases the degree of polymerization in these samples ${ }^{[19,20]}$

The band at $1094 \mathrm{~cm}^{-1}$ is attributed to the (C-C-C) bond that is associated to the presence of $\mathrm{CNT}$, which was also confirmed by XPS analysis of Figure $6 \mathrm{~b}$. The band at $1262 \mathrm{~cm}^{-1}$ is attributed to the asymmetric and symmetric stretching vibration of (C-O-C) groups belonging to 2-substituted furan rings. This band can also be related to the reaction between the CNT-f and the alcohol of furan ring, which increases the presence of C-O-C groups.

The elemental composition analyses were performed by XPS for the neat and functionalized CNTs. The neat CNT was a reference to evaluate the efficiency of functionalization with carboxylic groups. Figure 7 shows the curve fitting of $\mathrm{C}_{1 \mathrm{~s}}$ and $\mathrm{O}_{1 \mathrm{~s}}$ core levels ${ }^{[21-23]}$ for neat (Figure $7 \mathrm{a} 1$ and $7 \mathrm{a} 2$ ) and functionalized CNT with $\mathrm{H}_{2} \mathrm{SO}_{4}: \mathrm{HNO}_{3}$ (Figure $7 \mathrm{~b} 1$ and $7 \mathrm{~b} 2$ ), respectively. The $\mathrm{C}_{1 \mathrm{~s}}$ spectrum was deconvoluted in six components: C-C ( 284.52 eV), C-H ( 285.36 eV), C-O $(\sim 286.58 \mathrm{eV}), \mathrm{C}=\mathrm{O}(\sim 287.58 \mathrm{eV}), \mathrm{O}-\mathrm{C}=\mathrm{O}(\sim 288.58 \mathrm{eV})$, and plasmon p-p* $(\sim 290.82 \mathrm{eV})$. The oxidative treatment with $\mathrm{H}_{2} \mathrm{SO}_{4}: \mathrm{HNO}_{3}$ increases the carboxylic group in 
$288.58 \mathrm{eV}$, due to the insertion of oxygen onto the nanotube surface ${ }^{[20,24]}$. The curve at the $\mathrm{O}_{1 \mathrm{~s}}$ core level was fitted with three components, refering to $\mathrm{CO}(\sim 535.18 \mathrm{eV}), \mathrm{C}=\mathrm{O}, \mathrm{OH}$ $(\sim 532.04 \mathrm{eV}), \mathrm{O}^{-2}$ (iron oxide) $(\sim 531.01 \mathrm{eV})$. For oxidative treatments, the proportion of $\mathrm{OH}$ and $\mathrm{C}=\mathrm{O}$ bonds increased, which was mainly due to the presence of carboxylic groups.
Figure 8 shows the curve fitting of the $\mathrm{C}_{1 \mathrm{~s}}$ and $\mathrm{O}_{1 \mathrm{~s}}$ core levels in the cured PFA and its composite with $2.0 \mathrm{wt} \%$ of CNT-f. In Figure 8a1, the binding energies of curve fitting of $\mathrm{C} 1 \mathrm{~s}$ were identified and related to the bonds of the pure polymer by the numbering indicated in parenthesis in the figure. Four important bonds were identified $\mathrm{CH}$
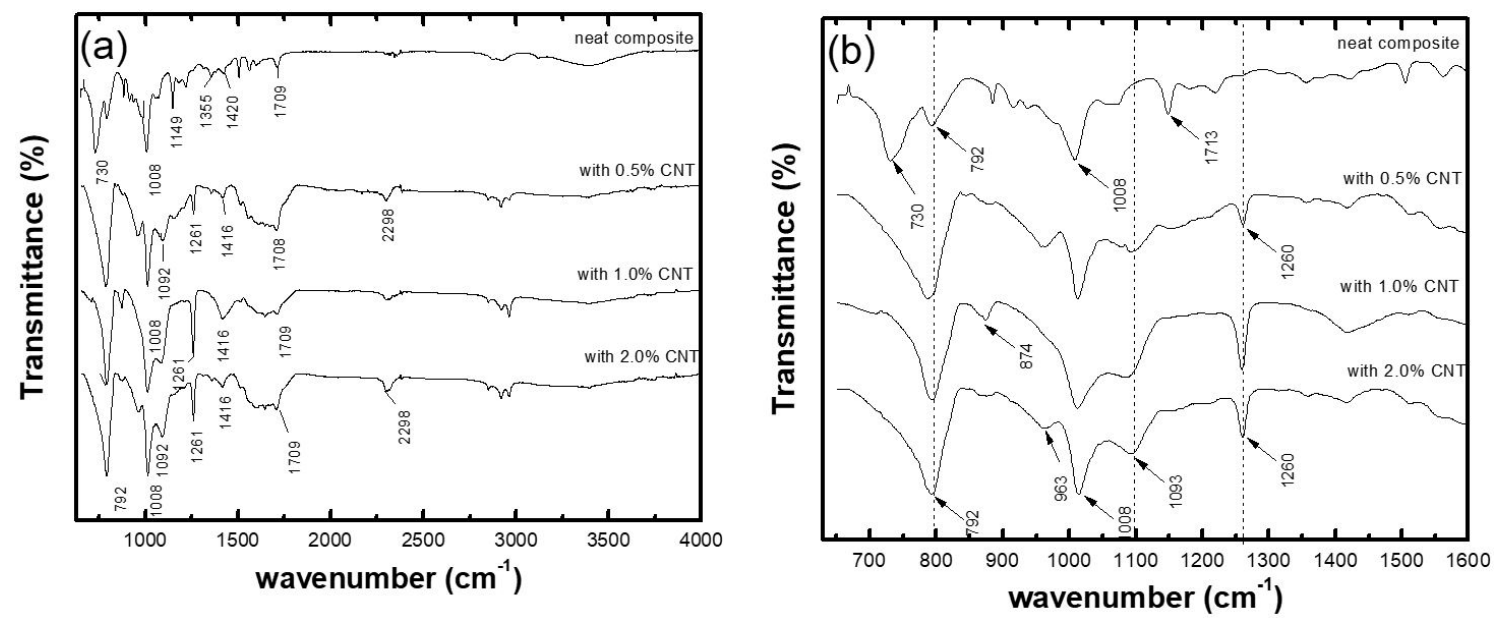

Figure 6. FTIR spectra with peaks identified for: (a) cured PFA and PFA composites and (b) Expansion of the region until $1600 \mathrm{~cm}^{-1}$ for the band analysis of cured PFA and PFA composites with $0.5,1.0$ and $2.0 \mathrm{wt} \%$ of functionalized CNTs.
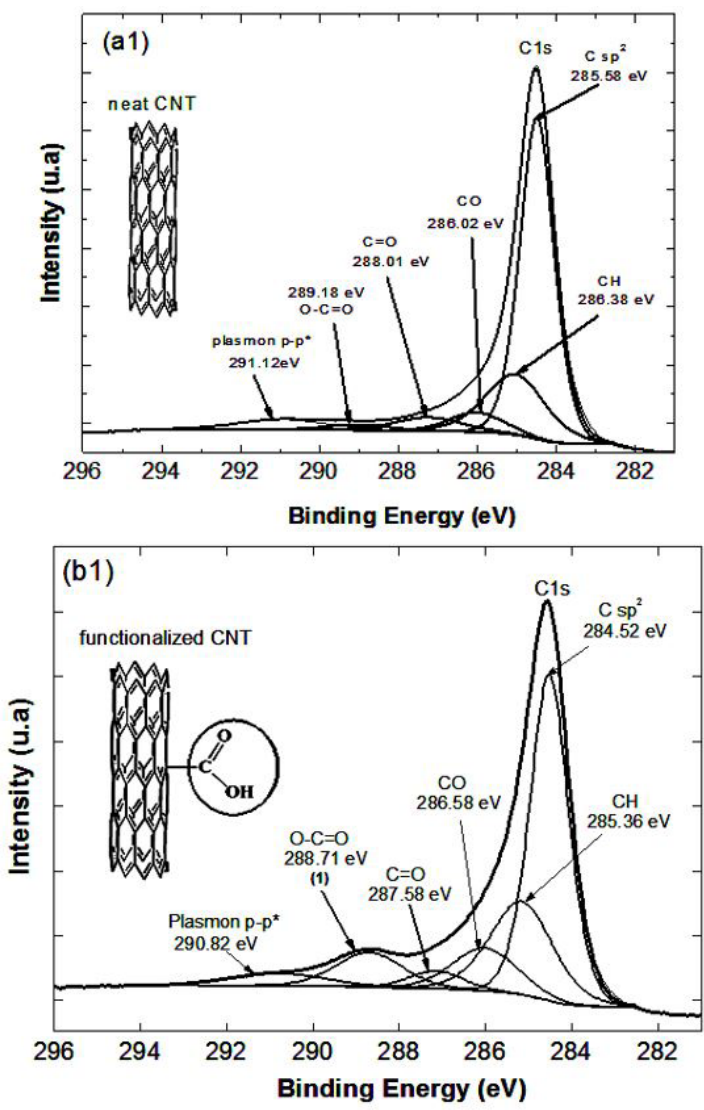
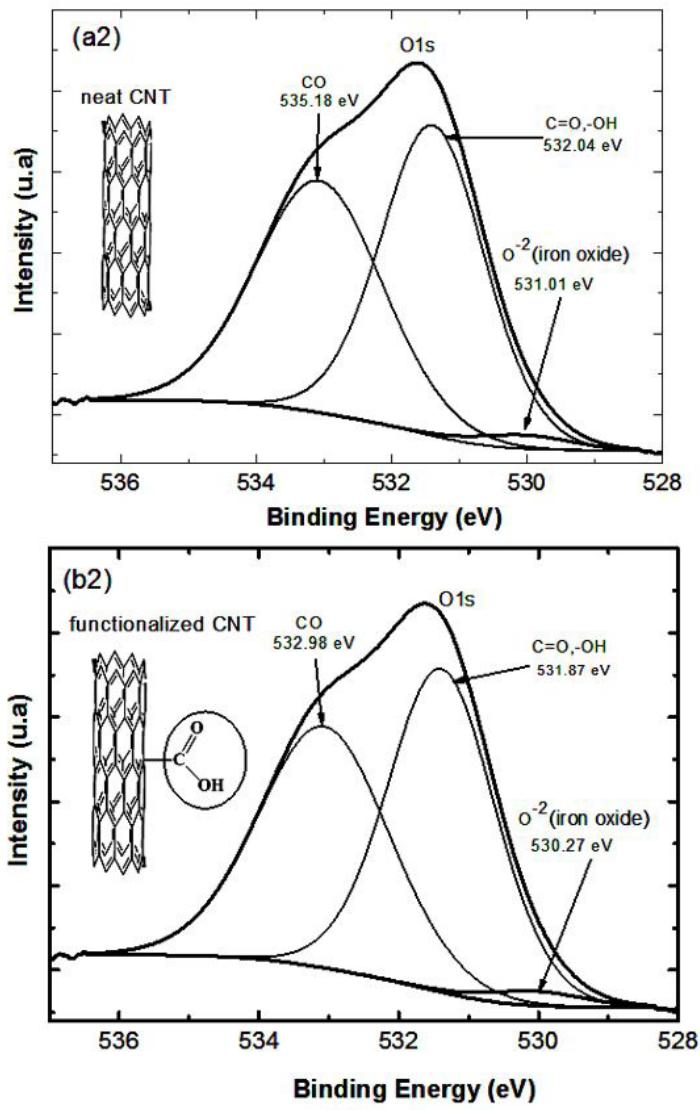

Figure 7. Curve fitting of $\mathrm{C} 1 \mathrm{~s}$ and $\mathrm{O} 1 \mathrm{~s}$ core levels for: (a1 and a2) neat and ( $\mathrm{b} 1$ and b2) functionalized $\mathrm{CNT}$ with $\mathrm{H}_{2} \mathrm{SO}_{4}: \mathrm{HNO}_{3}$. 

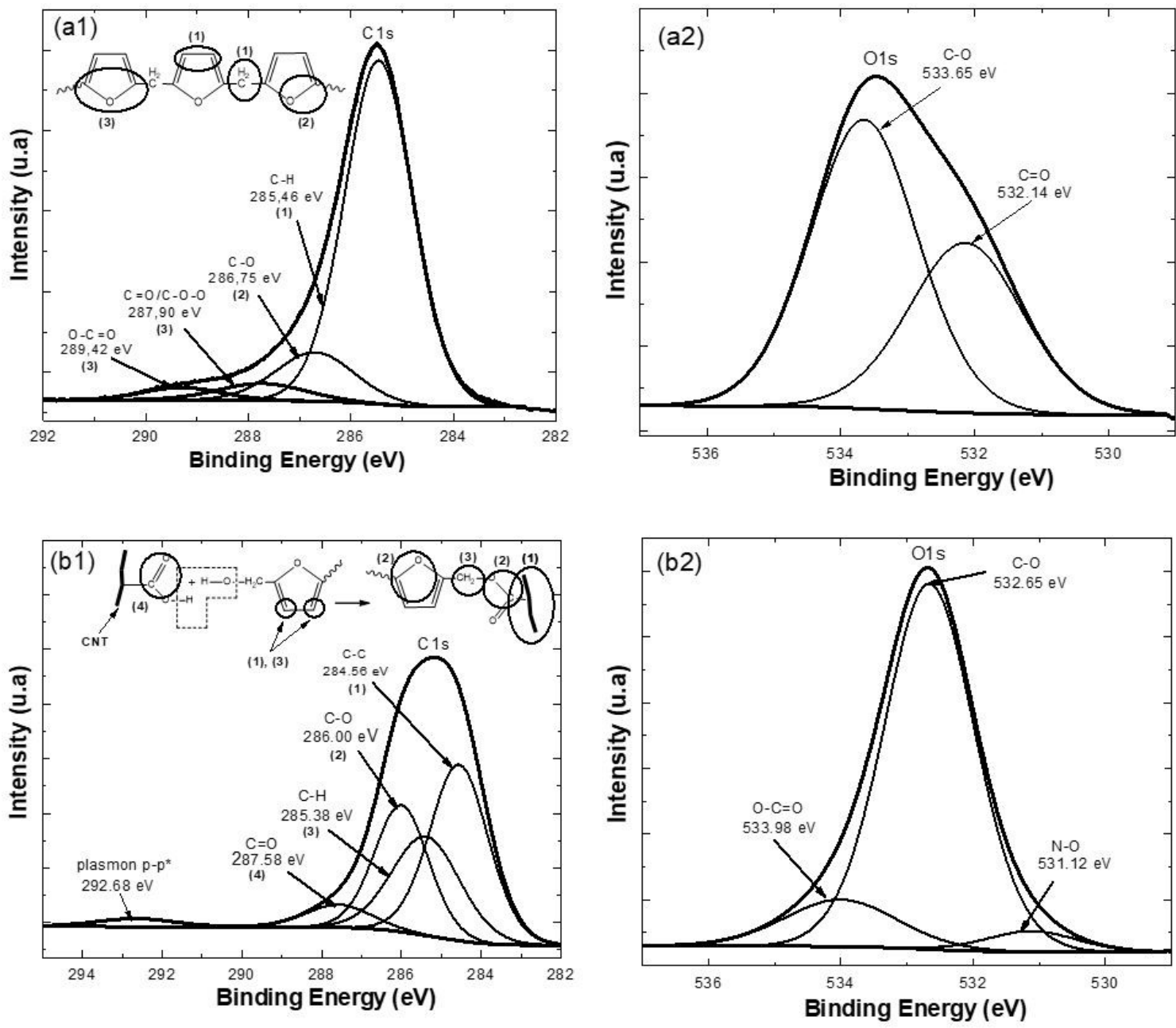

Figure 8. Curve fitting of $\mathrm{C} 1 \mathrm{~s}$ and $\mathrm{O} 1 \mathrm{~s}$ core levels for: (a1 and a2) PFA resin cured with APTS and (b1 and b2) curve fitting of C1s and $\mathrm{O} 1 \mathrm{~s}$ core levels for functionalized CNT with $\mathrm{H}_{2} \mathrm{SO}_{4}: \mathrm{HNO}_{3}$.

$(\sim 285.46 \mathrm{eV}), \mathrm{CO}(\sim 286.76 \mathrm{eV}), \mathrm{C}=\mathrm{O} / \mathrm{COO}(\sim 287.90 \mathrm{eV})$ and $\mathrm{O}-\mathrm{C}=\mathrm{O}(\sim 289.42 \mathrm{eV})$, with the latter showing a high intensity. In Figure 8a2, the binding energies for the pure material, were identified for the $\mathrm{O}_{1 \mathrm{~s}}$ core level with binding energies of $\mathrm{CO}(\sim 533.65 \mathrm{eV})$ and $\mathrm{C}=\mathrm{O}(\sim 532.14 \mathrm{eV})$. The results of these analyses were compared to the composite with $2.0 \mathrm{wt} \%$ of CNT-f cured under the same conditions. Figure $8 \mathrm{~b} 1$ shows the curve fitting of the $\mathrm{C}_{1 \mathrm{~s}}$ core levels for the composite with $2.0 \mathrm{wt} \%$ of CNT-f while important binding energies were also identified: $\mathrm{CC}(\sim 284.56 \mathrm{eV})$, $\mathrm{CH}(285.38 \mathrm{eV}), \mathrm{CO}(\sim 286.00 \mathrm{eV}), \mathrm{C}=\mathrm{O}(\sim 287.58 \mathrm{eV})$ and plasmon p-p* $(\sim 292.68 \mathrm{eV})$. There is a large decrease in relative binding intensity of $\mathrm{CH}(\sim 285.38 \mathrm{eV})$, increasing the $\mathrm{CO}(\sim 286.00 \mathrm{eV})$ and $\mathrm{C}=\mathrm{O}$ band $(\sim 287.58 \mathrm{eV})$. There is the appearance of the $\mathrm{C}-\mathrm{C}$ band $(\sim 284.56 \mathrm{eV})$, which refers to the presence of CNTs in the composite. The increase of the CO band $(\sim 286.00 \mathrm{eV})$ is probably related to the reaction of the hydroxyl group of carboxylic acid with the hydroxyl group of furan ring. The curve at the $\mathrm{O}_{1 \mathrm{~s}}$ core level in Figure $8 \mathrm{~b} 2$ was fitted with three components, refering to C-O $(\sim 532.65 \mathrm{eV})$, $\mathrm{O}-\mathrm{C}=\mathrm{O}(\sim 533.98 \mathrm{eV})$ and $\mathrm{N}-\mathrm{O}(\sim 531.12 \mathrm{eV})$. There is an increase in energy intensity of the $\mathrm{CO}$ bond, a disappearance of the $\mathrm{C}=\mathrm{O}$ bond and an emergence of the $\mathrm{O}-\mathrm{C}=\mathrm{O}$ bond in the composite. The appearance of the N-O bond is also observed, which is related to remaining traces of CNT-f.

Figure 9 shows the influence of CNT in the cure of neat PFA resin and with different percentages of CNT-f. According to our results, a relatively small amount of CNTs in PFA resin matrix is capable of significantly enhancing the viscoelastic properties and modifying the thermal stability, since it was observed that the initial cure temperature $\left(\mathrm{T}_{\text {gel }}\right)$ of PFA resin, when $0.5,1.0$ and $2.0 \mathrm{wt} \%$ of CNT is added, decreases this property at around $2^{\circ} \mathrm{C}, 5^{\circ} \mathrm{C}$ and $17^{\circ} \mathrm{C}$, respectively, when compared with neat PFA resin.

The CNTs bearing active groups can significantly change the surface characteristics of these constituents. These functionalized carbon nanotubes can react in different ways with several materials, such as thermoset and thermoplastic resins, or can act as a catalyst system, thus enhancing the interfacial bond between the matrix while the CNTs can dictate the application of different polymer nanocomposites. Thus, cured kinetic behavior of furfuryl alcohol resin is highly dependent on the nanocomposite constituents. 


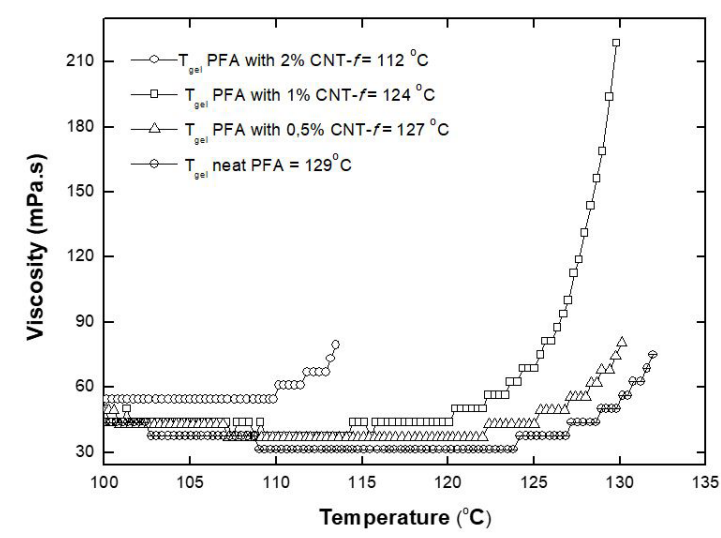

Figure 9. Viscosity behavior versus temperature for the cured resin with furfuryl resin reinforced with $0.5 \mathrm{wt} \%, 1.0 \mathrm{wt} \%$ and $2.0 \mathrm{wt} \%$ of purified NTC.

The reactivity of furfuryl groups probably increases with their nucleophilic nature and, when using an appropriate catalyst as well as an adequate curing temperature, it is possible to lead to a highly crosslinked network. On the other hand, the functionalization of CNTs increases their surface roughness and, when a chemical modification is used, the interaction between the nanotubes and the matrix is usually responsible for the strong adhesion, which is mainly due to the formation of covalent bonds at the interface. In general, after the functionalization of the nanotubes, the polar groups located on the surface of CNT act as curing agents and accelerate the curing reaction of the thermoset resins. That is, the chemical bonds formed by the carbon nanotubes add the chemical bonds formed by the catalyst (PTSA) accelerate cure.

\section{Conclusions}

We initially proposed reach an understanding of the chemical interaction mechanism of functionalized carbon nanotubes with carboxylic groups and Poly(furfuryl alcohol) (PFA) resin. The proposed mechanism was shown in Figure 1. This interaction was evident from the data of the FTIR and XPS of the composites. We confirmed this understanding by experimental techniques. Raman showed a functional group added to a wall of carbon nanotubes. The mixture of CNT-f with furfuryl alcohol (FA), in addition to facilitating mixing due to low viscosity, also facilitates the chemical bonds with the functional groups. It was observed that this chemical interaction occurs between CNT-f and furfuryl alcohol, followed by the addition to the PFA. The chemical interaction occurs between hydroxyl group in the polymeric chain and the carboxylic group with the subsequent output of one water molecule. The mixture of CNT-f in the furfuryl alcohol (FA), before being added to the PFA, can be considered a good procedure in order to obtain an adequate chemical interaction between CNT-f and PFA. Moreover, CNT-f acts as curing agent that accelerates the curing reaction of PFA and increases the degree of polymerization. Thus, it is important understand the chemical interaction between the carbon nanotube and the polymer matrix.
PFA resin has a wide range of applications such as adhesives, porous carbon, polymeric material, etc. Therefore, multifunctional composite materials reinforced with carbon nanotubes may provide a wide range of applications. From these results, it can be concluded that the process used in this study can contribute with some improvements regarding the manufacture of multifunctional composite materials for industrial applications.

\section{Acknowledgements}

The authors would like to thank FAPESP, CAPES, $\mathrm{CNPq}$ for the financial support received and INPE/DIMARE for the material. The authors declare that they have no conflict of interest.

\section{References}

1. Gandini, A. (2008). Polymers from renewable resources: a challenge for the future of macromolecular materials. Macromolecules, 41(24), 9491-9504. http://dx.doi.org/10.1021/ ma801735u.

2. Alimukhamedov, M. G., \& Magrupov, F. A. (2007). Kinetics of homopolycondensation of furfuryl alcohol. Polymer Science Series B, 49(7), 167-171. http://dx.doi.org/10.1134/ S1560090407070019.

3. Wang, H., \& Yao, J. (2006). Use of poly(furfuryl alcohol) in the fabrication of nanostructured carbons and nanocomposites. Industrial \& Engineering Chemistry Research, 45(19), 63936404. http://dx.doi.org/10.1021/ie0602660.

4. Men, X. H., Zhang, Z. Z., Song, H. J., Wang, K., \& Jiang, W. (2008). Functionalization of carbon nanotubes to improve the tribological properties of poly(furfurylalcohol) composite coatings. Composites Science and Technology, 68(3-4), 10421049. http://dx.doi.org/10.1016/j.compscitech.2007.07.008.

5. Xie, X. L., Mai, Y. W., \& Zhou, X. P. (2006). Dispersion and alignment of carbon nanotubes in polymer matrix: a review. Materials Science and Engineering R Reports, 49(4), 89-112. http://dx.doi.org/10.1016/j.mser.2005.04.002.

6. Ma, P. C., Siddiquia, N. A., Naromb, G., \& Kima, J. K. (2010). Dispersion and functionalization of carbon nanotubes for polymer-based nanocomposites: a review. Composites. Part A, Applied Science and Manufacturing, 41(10), 1345-1367. http://dx.doi.org/10.1016/j.compositesa.2010.07.003.

7. Choura, M., Belgacem, N. M., \& Gandini, A. (1996). Acidcatalyzed polycondensation of furfuryl alcohol: mechanisms of chromophore formation and cross-linking. Macromolecules, 29(11), 3839-3850. http://dx.doi.org/10.1021/ma951522f.

8. Bertarione, S., Bonino, F., Cesano, F., Damin, A., Scarano, D., \& Zecchina, A. (2008). Furfuryl alcohol polymerization in H-Y confined spaces: reaction mechanism and structure of carbocationic intermediates. The Journal of Physical Chemistry B, 112(9), 2580-2589. PMid:18266350. http:// dx.doi.org/10.1021/jp073958q.

9. Zhang, S., \& Solomon, D. H. (1997). The reaction of furfuryl alcohol resins with hexamethylenetetramine: a $13 \mathrm{C}$ and $15 \mathrm{~N}$ high-resolution solid-state NMR study. Journal of Polymer Science. Part B, Polymer Physics, 35(14), 2233-2243. http:/ dx.doi.org/10.1002/(SICI)1099-0488(199710)35:14<2233::AIDPOLB4>3.0.CO;2-X.

10. González, R., Figuero, J. M., \& González, H. (2002). Furfuryl alcohol polymerisation by iodine in methylene chloride. European Polymer Journal, 38(2), 287-297. http://dx.doi. org/10.1016/S0014-3057(01)00090-8. 
11. Antunes, E. F., Almeida, E. C., Rosa, C. B. F., Medeiros, L. I., Pardini, L. C., Massi, M., \& Corat, E. J. (2010). Thermal annealing and electrochemical purification of multi walled carbon nanotubes produced by camphor/ferrocene mixtures. Journal of Nanoscience and Nanotechnology, 10(2), 1296-1303. PMid:20352791. http://dx.doi.org/10.1166/jnn.2010.1830.

12. Datsyuk, V., Kalyva, M., Papagelis, K., Parthenios, J., Tasis, D., Siokou, A., Kallitsis, I., \& Galiotis, C. (2008). Chemical oxidation of multiwalled carbon nanotubes. Carbon, 46(6), 833-840. http://dx.doi.org/10.1016/j.carbon.2008.02.012.

13. Edwards, E. R., Antunes, E. F., Botelho, E. C., Baldan, M. R., \& Corat, E. J. (2011). Evaluation of residual iron in carbon nanotubes purified by acid treatments. Applied Surface Science, 258(2), 641-648. http://dx.doi.org/10.1016/j.apsusc.2011.07.032.

14. Bower, C., Kleinhammes, A., Wu, Y., \& Zhou, O. (1998). Intercalation and partial exfoliation of single-walled carbon nanotubes by nitric acid. Chemical Physics Letters, 288(2-4), 481-486. http://dx.doi.org/10.1016/S0009-2614(98)00278-4.

15. Gonzalez, R., Figueroa, J. M., \& Gonzalez, H. (2001). Furfuryl alcohol polymerization by iodine in methylene chloride. European Polymer Journal, 38(2), 287-297. http://dx.doi. org/10.1016/S0014-3057(01)00090-8.

16. Bertarione, S., Bonino, F., Cesano, F., Jain, E., Zanetti, M., Scarano, D., \& Zecchina, A. (2009). Micro-FTIR and microraman studies of a carbon film prepared from furfuryl alcohol polymerization. The Journal of Physical Chemistry B, 113(31), 10571-10574. PMid:19719270. http://dx.doi.org/10.1021/ jp9050534.

17. Shindo, A., \& Izumino, K. (1994). Structural variation during pyrolysis of furfuryl alcohol and furfural-furfuryl alcohol resins. Carbon N Y, 32(7), 1233-1243. http://dx.doi.org/10.1016/00086223(94)90107-4.

18. Oishi, S. S., Rezende, M. C., Origo, F. D., Damião, A. J., \& Botelho, E. C. (2013). Viscosity, pH, and moisture effect in the porosity of poly(furfuryl alcohol). Journal of Applied Polymer
Science, 128(3-5), 1680-1686. http://dx.doi.org/10.1002/ app. 38675 .

19. Barsberg, S., \& Thygesen, L. G. (2009). Poly(furfuryl alcohol) formation in neat furfuryl alcohol and in cymene studied by ATR-IR spectroscopy and density functional theory (B3LYP) prediction of vibrational bands. Vibrational Spectroscopy, 49(1), 52-63. http://dx.doi.org/10.1016/j.vibspec.2008.04.013.

20. Larciprete, R., Gardonio, S., Petaccia, L., \& Lizzit, S. (2009). Atomic oxygen functionalization of double walled carbon nanotubes. Carbon, 47(11), 2579-2589. http://dx.doi. org/10.1016/j.carbon.2009.05.008.

21. Kónya, Z., Vesselényi, I., Kiss, J., Farkas, A., Oszkó, A., \& Kiricsi, I. (2004). XPS study of multiwall carbon nanotube synthesis on Ni-, V-, and Ni, V-ZSM-5 catalysts. Applied Catalysis A, General, 260(1), 55-61. http://dx.doi.org/10.1016/j. apcata.2003.10.042.

22. Shulga, Y. M., Tien, T. C., Huang, C. C., Lo, S. C., Muradyan, V. E., Polyakova, N. V., Ling, Y. C., Loutfy, R. O., \& Moravsky, A. P. (2007). XPS study of fluorinated carbon multi-walled nanotubes. Journal of Electron Spectroscopy and Related Phenomena, 160(1-3), 22-28. http://dx.doi.org/10.1016/j. elspec.2007.06.002.

23. Maruyama, T., Bang, H., Fujita, N., Kawamura, Y., Naritsuka, S., \& Kusunoki, M. (2007). STM and XPS studies of early stages of carbon nanotube growth by surface decomposition of $6 \mathrm{H}-\mathrm{SiC}(000-1)$ under various oxygen pressures. Diamond and Related Materials, 16(4-7), 1078-1081. http://dx.doi. org/10.1016/j.diamond.2007.01.004.

24. Naeimi, H., Mohajeri, A., Moradi, L., \& Rashidi, A. M. (2009). Efficient and facile one pot carboxylation of multi-walled carbon nanotubes by using oxidation with ozone under mild conditions. Applied Surface Science, 256(3), 631-635. http:// dx.doi.org/10.1016/j.apsusc.2009.08.094.

Received: July 13, 2016 Accepted: Dec. 12, 2016 